\title{
Factors Associated with Methicillin Resistant Staphylococcus aureus Carriage
}

\author{
Masood Abdulkareem Abdulrahman \\ Community Health Department \\ Shekhan Technical College of Health \\ Duhok Polytechnic University \\ Duhok, Iraq \\ masood.abdulkareem@dpu.edu.krd
}

\author{
Arazoo Issa Taher \\ Nursing Department \\ Bardarash Technical Institute \\ Duhok Polytechnic University \\ Duhok, Iraq \\ Arazoo.taher@dpu.edu.krd
}

\begin{abstract}
Volume 4 - Special Issue: 3rd International Conference on Health \& Medical Sciences: Insight into Advanced Medical Research (ICHMS 2019)
\end{abstract}

DOI:

10.24017/science.2019 .ICHMS.9

Received:

6 June 2019

Accepted:

8 July 2019

\section{Abstract}

S. aureus is a common commensal of the skin and mucosal membranes of humans, with estimates of $20 \%$ (range from $12 \%$ to $30 \%$ ) of healthy people are persistent S. aureus nasal carriers, $30 \%$ (range from $16 \%$ to $70 \%$ ) are intermittent carriers, and $50 \%$ (range from $16 \%$ to $69 \%$ ) are non-carriers. The aim of this article is to explore the factors associated with Methicillin Resistant Staphylococcus Aureus carriage among food handlers. Across sectional study was done to involve 200 persons who are handling foods in 40 restaurants in Duhok city in the study. Methicillin Resistant Staphylococcus Aureus was detect among $27 \%$ of studied population. Methicillin Resistant Staphylococcus Aureus carrier rate showed a significant association with skin and soft tissue infections, health facilities visits and certain jobs of food handlers. Age, duration of work in the restaurants, personal protective measures and antibiotic use showed no significant association with the prevalence of MRSA. Methicillin Resistant Staphylococcus Aureus carrier rate was higher among food handlers working in popular restaurants when compared to other restaurants. Ongoing screening of all persons who handled foods is crucial to detect and treat those are MRSA carrier as one of major public health issues.

Keywords: Methicillin Resistant Staphylococcus aureus , Fac carrier state , Duhok 
Staphylococci are worldwide bacteria, which include over 32 species and subspecies [1]. S. aureus is among the most ubiquitous and important pathogens among Staphylococci species. The discovery of S. aureus was in 1880 by Alexander Ogston. It is particularly resistant to unfavorable environmental conditions and it resists drying beside high $\mathrm{NaCl}$ concentrations. This permits a probably temporary and even permanent colonization of skin and nasal mucosa [2 ]. It is frequently found in both community and nosocomial and it is a commensal bacterium of human skin and anterior nares, but commonly causes severe infections in humans when the immune system weakness [3,4].

It is also associated with life-threatening conditions including; septicemia, infection of lung, bone ,endocardium and toxic shock syndrome. In addition, it causes various mild dermis and subskin infections. It colonizes not only the nasal cavity but also other anatomical sites namely, the axilla, pharynx and genital area [5,6]. Moreover, S. aureus considered an important causative agent of food poisoning. The carriage, also called colonization, can be defined as the presence of bacteria on or in the body without causing illness. Although different sites of human body may be colonized but the anterior nasal cavity are the predominant site for $S$. aureus carriage. Another anatomical sites that commonly sanctuary S. aureus include the skin, anal region, and oral cavity. Most published articles on nasal carrier of the organism used with one nasal culture to decide whether the studied population harbor the organism or not. S. aureus carriers classified into persistent carriers and intermittent carriers $[6,7]$.

Approximately $50 \%$ of h e a l th y i n d i v i d u a l s classified as S. aureus nasal carriers $[20 \%$ persistent and $30 \%$ intermittent carriers]. Persistent carriers ordinarily bear the same strain of the organism for prolonged time, while for intermittent carriers they harbor various strains during different times [8]. These features are crucial because the persistent carriers have excessive bacterial loads and are at greater hazards for developing $S$. aureus infection. It is especially significant in the healthcare facilities like hospital environment where the carrier persons and infected patients act as the most crucial source of MRSA in these facilities. Preceding antibiotic therapy, long stay in hospitals, history of surgical operations, living in a nursing house, and close contacts to a sick person either carrier or infected with MRSA are considered to be factors related to MRSA carriage. The prevalence rate of MRSA among persons without typical risk factors persists approximately low $(\leq 0.24 \%)$ in spite of the increasing CA-MRSA infections. According to a nationwide survey done by the Centre for Disease Control and Prevention (Atlanta), 32.4\% of Americans' populations carried $S$. aureus in their noses and $0.8 \%$ of them a re MRSA carries. Although carriers do not have infections, they can spread Staphylococcus to people with whom they have physical contact and can shed Staphylococcus into the environment. This can result in further people becoming carriers or harboring an infection [6,9].

The morbidity and mortality of $S$. aureus infections continue to exist despite utilizing antibiotics to treat these infections, relatively it may be due to the capability of $S$. aureus to become resistant to multiple commonly used antibiotics. S. aureus is regularly carried by healthy individuals in the nose and, in the skin and mucous membranes. Carriers are considered as a source of infection to others and themselves [10]. The major sources of infections inhuman being are fomites contaminated, airway tract and skin. Direct transmission of infection has supposed added significance in hospitals, where a large proportion of the staff and patients may carry antibiotic- resistant staphylococci in the nose and or on the skin, especially those that resist MRSA and VRSA (Vancomycin resistance Staphylococcus aureus). About two billion people worldwide carry S. aureus and 53 million (2.7\%) of carriers carry MRSA [11]. MRSA is one of the main human pathogens throughout the world. The epidemiological trend of MRSA is regularly altering, and both circulating clones and their antibiotic resistance profiles differ significantly over regions and countries. Epidemiologic information collected via continuous surveillance is important to support clinicians and infection control committees in their try to inhibit and treat the infection. The development of colonization in patients and hospital workers frequently happens. 
Transmission of S. aureus may occur through direct contact with unwashed, contaminated hands and by inanimate objects (fomites). Both nosocomial and community infections caused by MRSA have become a main health care concern[12,13]. The aim of this article is to explore the factors associated with MRSA carriers among food handlers.

\section{SUBJECTS AND METHODS}

This study was conducted in restaurants in Duhok city. Duhok is one of the four governorates of Kurdistan Region of Iraq. There were (314) restaurants of different types in Duhok city at the study time. These restaurants were classified into three types (groups) including basic, fast food and high-class restaurants depending on the type of services.

1. Basic restaurants: They constitute about $69.7 \%$ (219) of total restaurants. They are middle priced restaurants and provide table services. Basic restaurants come between fast food establishments and high-class restaurants in terms of pricing.

2. Fast food restaurants: They are the second common type of restaurants in Duhok city and defined by Oxford as a "food that is easily prepared, processed and served in snack bars and restaurants as a quick meal or to be taken away" [14]. They constitute 54(17.2\%) restaurants in this city. Most of fast food restaurants are close to markets and shopping malls. These meals consist primarily of burgers, Doner kebab, potato chips , pizzas, falafel and sandwiches .

3- High class restaurants: They represent only 41 (13.1\%) restaurants in Duhok city. These restaurants located in different areas in the city. These restaurants provide full services and frequented by stars and high-profile persons.

200 persons who are handling foods (cooks, waiters and kitchen assistants) are selected from 40 different restaurants by multi stage sampling methods. For each food handlers' swabs are taken from nostrils and both hands involving wrist of hands and in between fingers about five seconds for each hand. The swabs transferred into transport media then cultured in Mannitol salt agar and incubated aerobically at $37^{\circ} \mathrm{C}$ for 24 to 48 hours. Then isolates were considered $S$. aureus by using gram staining, standard biochemical reactions (catalase and coagulase tests) and fermentation on mannitol salt agar. Antimicrobial susceptibility was performed on Mueller-Hinton agar using Kirby-Bauer disk diffusion method according to diameter interpretation standards charts.

\section{Ethical considerations}

All required administrative and ethical approvals were arranged and obtained at both academic level ( Technical College of Health -DPU) and the Research Ethical Committee of the Directorate General of Health in Duhok Governorate before conducting this research, and at individual level an oral informed agree was acquired .

\section{Data analysis}

All data related to demographic information were entered and edited using Microsoft Word 2010. Descriptive statistics was provided for the demographic data and responses of the questionnaire. For testing association of the studied variables with MRSA SPSS 23 and Chisquare test was used. $P$-values $\leq 0.05$ was used to indicate significant association of age, type of work, type of restaurants, duration of work, and antibiotic used with MRSA status of workers who participated in the study.

\section{RESULTS}


Out of 200 collected samples from food handlers, 74 (34\%) isolates were identified as S. aureus by producing golden yellow colonies on MSA and gram- stain showed G+ irregular cluster of cocci, catalase and coagulase were also positive. Moreover, $27 \%$ of isolates were confirmed as MRSA by giving inhibition zone of less than $\geq 9$ for methicillin disc. Furthermore, no VRSA isolates could be detected within food handlers.4

\subsection{Association between duration of work and MRSA status}

No significant statistical association was found between duration of work in the restaurants and MRSA status, however, the number of MRSA carrier cases increased with years of work. It was from $20.3 \%$ for less than one-year work duration and $31.2 \%$ for 5 years or more Table 1.

Table 1: Duration of work in the restaurants and MRSA status

\begin{tabular}{|l|l|l|l|}
\hline \multirow{2}{*}{$\begin{array}{l}\text { Duration of work in } \\
\text { restaurants }\end{array}$} & \multicolumn{2}{|l|}{ MRSA status } & $\begin{array}{l}\text { Total } \\
\text { No. (\%) }\end{array}$ \\
\cline { 2 - 4 } & Positive (\%) & Negative (\%) & $74(37)$ \\
\hline >1year & $15(20.3)$ & $59(79.7)$ & $61(35)$ \\
\hline 2-4 years & $19(31.2)$ & $42(68.8)$ & $64(32)$ \\
\hline Total & $20(31.2)$ & $44(68.8)$ & 200 \\
\hline
\end{tabular}

$P$-Value $=0.259$

\subsection{Association between health facilities visits and MRSA status}

A significant association between a number of hospital visits and MRSA carrier rates was detected. The highest MRSA carrier rate 100\% (23 cases) was observed among those who visited hospitals 5-6 times. In contrary, the lowest MRSA carrier rate (2.6\%) was seen among those who did not visit hospitals Table 2 .

Table 2 Association between health facilities visits and MRSA status

\begin{tabular}{|l|l|l|l|}
\hline $\begin{array}{l}\text { Number of health } \\
\text { facilities visits during the }\end{array}$ & \multicolumn{2}{|l|}{ MRSA status } & \multirow{2}{*}{$\begin{array}{l}\text { Total } \\
\text { No. (\%) }\end{array}$} \\
\cline { 2 - 4 } last 6 months & Positive (\%) & Negative (\%) & 16 \\
\hline 2-4 visits & $16(100)$ & $0(0.0)$ & 23 \\
\hline 5-6 visits & $23(100)$ & $0(0.0)$ & 11 \\
\hline 7and more & $11(100)$ & $0(0.0)$ & 150 \\
\hline No visits & $4(2.6)$ & $146(97.3)$ & 200 \\
\hline Total & $54(27)$ & $146(73)$ & \\
\hline
\end{tabular}

$P$-Value $<0.001$

\subsection{Association with antibiotic utilization}

There was no significant association between antibiotic utilization and MRSA carrier rate. The highest percentage $30.4 \%$ of MRSA carrier was isolated from food handlers who did not use antibiotics Table 3.

Table 3: Association with antibiotic utilization

\begin{tabular}{|l|l|l|l|}
\hline \multirow{2}{*}{$\begin{array}{l}\text { Have you been using } \\
\text { antibiotics continuously } \\
\text { in the last 30 days }\end{array}$} & MRSA status & $\begin{array}{l}\text { Total } \\
\text { No. }\end{array}$ \\
\cline { 2 - 4 } Yes & Positive (\%) & Negative (\%) & 52 \\
\hline No & $9(17.3)$ & $43(82.6)$ & 148 \\
\hline Total & $45(30.4)$ & $103(69.5)$ & 200 \\
\hline
\end{tabular}

$P$-Value $=0.067$

\subsection{Distribution between Jobs of food handlers and MRSA status}


Job of food handlers has a significant association with MRSA carrier rate was seen. The highest proportion of MRSA was observed among cooks (36.9\%), followed by waiters and kitchen assistants (22.5\%), (22.9\%), respectively Table 4.

Table 4: Distribution between Jobs of food handlers and MRSA status

\begin{tabular}{|c|c|c|c|}
\hline \multirow{2}{*}{$\begin{array}{l}\text { Duration of work in } \\
\text { restaurants }\end{array}$} & \multicolumn{2}{|l|}{ MRSA status } & \multirow{2}{*}{$\begin{array}{l}\text { Total } \\
\text { No. }\end{array}$} \\
\hline & Positive (\%) & Negative (\%) & \\
\hline Cooks & 27 (36.9) & $46(63.0)$ & 73 \\
\hline Waiters & $16(22.5)$ & $55(77.4)$ & 71 \\
\hline Kitchen assistants & $11(22.9)$ & $37(77.0)$ & 48 \\
\hline Others & $0(0.0)$ & $8(100.0)$ & 8 \\
\hline Total & $54(27)$ & $146(73)$ & 200 \\
\hline
\end{tabular}

$P$-Value $=0.05$

\subsection{Frequency between age groups and MRSA status}

The highest percentage (35.2) of MRSA carrier rate was detected among the younger age group 20-29 years and a fewer percentage $20.7 \%$ was identified among the age groups of less than 20 years as well as the group of 40 years or above. Nevertheless, there was no significant association with different age groups and carrier rate Table 5.

Table 5: Frequency between age groups and MRSA status

\begin{tabular}{|l|l|l|l|}
\hline \multirow{2}{*}{ Age group } & \multicolumn{2}{|l|}{ MRSA status } & \multirow{2}{*}{$\begin{array}{l}\text { Total } \\
\text { No. }\end{array}$} \\
\cline { 2 - 3 } & Positive (\%) & Negative (\%) & 29 \\
\hline$<20$ & $11(20.4)$ & $18(12.3)$ & 80 \\
\hline $20-29$ & $19(35.2)$ & $61(41.8)$ & 38 \\
\hline $30-39$ & $13(24.1)$ & $25(17.1)$ & 53 \\
\hline 40 and above & $11(20.4)$ & $42(28.8)$ & 200 \\
\hline Total & $54(27)$ & $146(73)$ & \\
\hline
\end{tabular}

$P$-Value $=0.23$

3.6 Association between personal protective measures and MRSA status

The majority of food handlers $59.5 \%$ used personal protective measures. A (25\%) of positive MRSA cases used personal protective measures and the rest (29\%) did not. The association between using personal protective measures and MRSA status was not significant Table 6.

Table 6: Association between Personal protective measures and MRSA status

\begin{tabular}{|l|l|l|l|}
\hline \multirow{2}{*}{$\begin{array}{l}\text { Using personal } \\
\text { protective measures }\end{array}$} & \multicolumn{2}{|l|}{ MRSA status } & $\begin{array}{l}\text { Total } \\
\text { No. }\end{array}$ \\
\cline { 2 - 4 } & Positive (\%) & Negative (\%) & 119 \\
\hline Yes & $30(25)$ & $89(75)$ & 81 \\
\hline No & $24(29)$ & $57(61)$ & 200 \\
\hline Total & $54(27)$ & $146(73)$ & \multicolumn{2}{|l}{} \\
\hline
\end{tabular}

$P$ - Value $=0.49$

\subsection{Skin and soft tissue infection and MRSA status}


All food handlers (9) with skin infection had positive MRSA status, while $83.3 \%$ of all positive MRSA did not have skin lesions. The presence of skin lesions has a highly significant association with carrier status Table 7.

Table 7: Association between skin and soft tissue infection and MRSA status.

\begin{tabular}{|l|l|l|l|}
\hline \multirow{2}{*}{ Presence of infection } & \multicolumn{2}{|l|}{ MRSA status } & \multirow{2}{*}{$\begin{array}{l}\text { Total } \\
\text { No. }\end{array}$} \\
\cline { 2 - 4 } & Positive (\%) & Negative (\%) & 9 \\
\hline Yes & $9(100)$ & $0(0.0)$ & 191 \\
\hline No & $45(33)$ & $146(100.0)$ & 200 \\
\hline Total & $54(27)$ & $146(73)$ & \multicolumn{2}{|l}{} \\
\hline
\end{tabular}

$P$-Value $<0.001$

\subsection{Types of restaurants and MRSA status}

MRSA carrier rate has a highly significant association with different types of restaurants. A significant proportion (60\%) of MRSA was diagnosed in basic restaurants as it accommodated the largest number of food handlers. In comparison, high class restaurants and fast food restaurants had fewer MRSA rates 16\%, Table 8.

Table 8: Association between Types of restaurants and MRSA status

\begin{tabular}{|l|l|l|l|}
\hline \multirow{2}{*}{$\begin{array}{l}\text { Using personal protective } \\
\text { measures }\end{array}$} & \multicolumn{2}{|l|}{ MRSA status } & Total \\
\cline { 2 - 3 } & Positive (\%) & Negative (\%) & 105 \\
\hline Basic restaurants & $41(60)$ & $64(43.8)$ & 36 \\
\hline Fast food restaurants & $5(16)$ & $31(21.2)$ & 59 \\
\hline High class restaurants & $8(16)$ & $51(29.5)$ & 200 \\
\hline Total & $54(27)$ & $146(73)$ & \\
\hline
\end{tabular}

$P$-Value $<0.00$

\section{DISCUSSION}

In different communities the MRSA carrier status shows steadily increasing in the prevalence rate and this appears mainly among individuals that are not exposed to healthcare-associated risk factors for MRSA acquisition [15]. Infections due to community acquired -CA MRSA have been identified in a variety of populations, involving neonates, children, athletes, prisoners, military personnel. The most popular infections of CA-MRSA are soft tissue and skin infections. Successfully, many of this CA-MRSA strains have so far included susceptibility to a number of non-beta-lactam antimicrobials, though the majority of nosocomial MRSA infections are hardly cured because they resist multi-antibiotics [16]. Utilizing antibiotics is deem as a risk factor for the emergence of CA-MRSA infection [17].

\subsection{Duration of work}

The relation between duration of work and MRSA in the present study was not significant. Similar results were obtained by $[18,19]$. Though, a study done by Eveillard et al (2004) on hospital employees showed that the duration of work increases the risk of MRSA rate [20].

\subsection{Health facility visits}

Previous hospital visits considered one of the risk factors to harbor $S$. aureus so that in various studies done on CA-MRSA considered visiting the hospitals as a risk factor for getting the bacteria from the hospital. In the study on progress; a significant association between hospital visits and MRSA was found. Supporting this theory Pathare et al (2015) demonstrated that MRSA among the healthy hospital's visitors $18 \%$ is higher compared to $13.8 \%$ among health 
care staff in the hospitals [21]. This may be due to the continuous effective infection control policies and proper personal hygiene practices like hand washing in hospitals which might cause a lower prevalence of MRSA among healthcare personnel, contradictory, the higher prevalence among health community visitors might be they acquired in and out of hospital setting. In a meta-analysis review of 57 studies on CA-MRSA and human acquired HA-MRSA, the researchers detected that the prevalence of MRSA among community was somewhat low.

Nevertheless, $47.5 \%$ of healthy MRSA carriers and up to $85 \%$ of hospitalized patients diagnosed with CA carriers were found to have at least more than one year contact with health facilities related risk factors like recent hospital admission, health care facilities visits, chronic diseases like diabetes, and renal failure[22]. In a large meta-analysis study, the researchers detected that most of healthy people with CA-MRSA had more than oneyear healthcare-associated risk, which explained the low prevalence of MRSA among persons without risks remains low[15].

\subsection{Antibiotic use and MRSA status}

Salgado et al mentioned that continuous use of broad-spectrum antibiotics may be regarded ae a risk factor that associated with CA- MRSA spread in the community [15]. However, in this study, no significant statistical association between antibiotic usage and MRSA status was detected. In Atlanta, Georgia, a study done on common risk factors that associated with bacterial colonization with MRSA in hospitalized patients, Hidron et al (2005) found that receipt of antibiotics was one of the independent factors for MRSA colonization[23]. Similar to our findings was a study done in a military training center in San Diego, USA; the researchers found that there is no association between past antibiotic usage and MRSA status [24].

\subsection{Job type and MRSA}

It is proven by many researchers that the favorable prevalence is among workers who have contacts with foods that allow S. aureus to grow. However, the differences in results might be attributed to different factors like, educational level, cleaning behavior, the hygiene equipment and the work environment [19,25].

The highest proportion of MRSA was observed among cooks (36.9\%), followed by waiters and kitchen assistants. These results as supported by Ho et al who showed that colonizing rate was considerably higher in workers (chefs) handling raw meats 30\% than in non-exposed workers (other staff) 13\%[25] .Moreover, Kasturwar and Shafee (2011) found the highest MRSA prevalence among participants working in serving and preparing food $19.30 \%, 9.6 \%$ respectively[26]. The authors explained that the majority of workers 50 (60.2\%) were involved in serving the food to consumers and they are the core group among food handlers who are mainly involved in the transmission of FBDs. While Ferreira et al (2014) concluded that the presence of MRSA was not related to a certain job duty of the food handlers in the restaurants of governmental health facilities [27].

\subsection{Personal protective measures}

The majority of food handlers $25 \%$ in our study used personal protective measures and there was no significant association between using protective measures and MRSA status in this study. Although, theoretically using protective measures like glove, hats, masks, apron ...etc. may inhibit the hazard of microbial cross-contaminations but the researchers reported that neither the use of gloves nor even the pursuit of hand washing will decrease the risk of microbial cross-contaminations. Nonetheless, combining both practices together will decrease the risk of cross-contaminations. No or scarce published articles documented that food cater by gloved hands is safer than food cater by ungloved (bare) hands. This may be due to the fact that the many microorganisms like bacteria will adhere to the external surfaces of gloves and if not changed regularly, it could be a source of cross-contamination similar to unwashed hands 
and poor personal hygiene practices of food handlers which frequently contributes to food borne diseases outbreaks [28,29].

Continuous changing of gloves and effective hand washing before wearing and good quality gloves may increase the effectiveness of wearing gloves when touching unwrapped food. Furthermore, the puncture of gloves during working may increase the risk of contamination. It is important to educate food handlers about proper hand washing and wearing protective measures (Montville and [28,30].

Meanwhile, wearing hats is also an important protective measure neglected by many workers because the foods may be contaminated by falling hair or dandruff. Using protective measures during sneezing or cleaning nostrils is also significant to decrease cross-contamination [31]. These findings illustrate that proper hand washing and using gloves should be applied parallel to each other so as to forbid cross-contamination and limit the risk of food poisoning.

\subsection{Cutaneous and soft tissue infection and MRSA}

In this study, a highly significant association was found between skin and soft tissue infection and MRSA. This result was similar to what if found in Denmark, and in Georgia [32,33]. Furthermore to a large systematic review done in Custodial population between the years of 1997 to 2015, nearly seventeen studies concluded that cutaneous and soft tissue infections are related to highest documented rates of MRSA rate [34]. While, in Egypt (El-Shenawy el $a l$, 2014) showed that the MRSA carrier rate has no any significant statistical association with cutaneous and soft tissue infections [19].

\section{CONCLUSION}

Methicillin Resistant Staphylococcus aureus carrier rate was higher among food handlers working in popular restaurants when compared to other restaurants. MRSA carrier rate showed a significant association with cutaneous and soft tissue infections, hospital visits, and certain jobs of food handlers. Age, duration of work in the restaurants and antibiotic use showed no significant association with the prevalence of MRSA. Ongoing screening of all persons who handled foods is crucial to detect and treat those are MRSA carrier as one of major public health issues. Personal protective measures such as gloves, head covers and continuous changing it are highly advisable among food handlers.

\section{REFERENCE}

[1] M Haghkhah . Study of Virulence Factors of Staphylococcus aureus. Ph.D Thesis, Faculty of Biomedical and Life Sciences. Glasgow University Glasgow, Scotland, 2003.

[2] N Plipat.. Methicillin-resistant Staphylococcus aureus (MRSA) exposure assessment in hospital environment. University of Michigan, USA.pp.1-26,2012.

[3] DP Kateete , C N Kimani , F A Katabazi , A Okeng ,MS Okee, A Nanteza et al . Identification of Staphylococcus aureus: DNase and Mannitol salt agar improve the efficiency of the tube coagulase test. Ann Clin Microbiol Antimicrob; 9 (23): 1-7,2010. doi:10.1186/1476-0711-9-23.

[4] T Kitti , K Boonyonying, S Sitthisak. Prevalence of methicillin-resistant Staphylococcus aureus among university students in Thailand. Southeast Asian J Trop Med Public Health; 42(6): 1498-1504 ,2011.

[5] Q Rao , X Rao , X Hu , W Shang . Staphylococcus aureus ST121: a globally disseminated hypervirulent clone. J Med Microbiol; 64: 1462-73,2015. DOI 10.1099/jmm.0.000185.

[6] A Aryee and JD Edgeworth . Carriage, Clinical Microbiology and transmission of Staphylococcus aureus. In: F Bagnoli , R Rappuoli , G Grandi , editors. Staphylococcus aureus: Microbiology, Pathology, Immunology, Therapy and Prophylaxis. Springer International Publishing Switzerland.pp.1-14,2017. DOI 10.1007/ 82_ 20165.

[7] K Becker. Pathogenesis of Staphylococcus aureus. In: Fetsch A, editor. Staphy. aureus. UK: Elsevier Inc.pp. 1316,2018. Available from https://doi.org/10.1016 /B978-0-12-809671-0.00002-4.

[8] YA Que and PH Moreillon . Gram-Positive Cocci: Staphylococcus aureus (Including Staphylococcal Toxic Shock Syndrome). In: J E Bennett, M J Blaser, R Dolin, R G Douglas , G L Mandell, editors. Mandell, Douglas, and Bennett's Principles and practice of infectious diseases. 8th ed. Canada: Elsevier Saunders.pp. 2237-371,2015. 
[9] R E Rohde . Prevention, Treatment, and Containment of Staphylococcal Infections in Communities. USA: Texas State University-San Marcos.pp.1-47, 2007.

[10] R P Harvey , P C Champe , B D Fisher . Lippincott's Illustrated Reviews: Microbiology. 2nded. Hagerstown, MD. USA: Lippincott Williams and Wilkins. pp.69-75, 2007.

[11] K C Carroll . The staphylococci In:G F Brooks , E Jawetz, J L Melnick , E A Adelberg, editors. Jawetz, Melnick \& Adelberg's medical microbiology. 26 th ed. London: McGraw-Hill. pp.199-205,2013.

[12] L S Monson . Staphylococci. In: C R Mahon, DC Lehman, G Manuselis , editors. Textbook of diagnostic microbiology. 5th ed. China: Elsevier, Inc. pp. 314-25,2015.

[13] L G Baptistão , N C Silva ,E C Bonsaglia , B F Rossi , I G Castilho , A R Fernandes et al. Presence of Immune Evasion Cluster and Molecular Typing of Methicillin-Susceptible Staphylococcus aureus Isolated from Food Handlers. J Food Prot; 79(4): 682-86,2016. doi: 10.4315/0362-028X.JFP-15-401.

[14] English Oxford Living Dictionary. Definition of fast food in English [Cited 2018 October 20] available https:// en. Oxford dictionaries. Com/definition / fast_food.

[15] CD Salgado, B M Farr , D P Calfee . Community-acquired methicillin- resistant Staphylococcus aureus: a metaanalysis of prevalence and risk factors. Clin Infect Dis; 36(2): 131-39,2003.

[16] World Health Organization. Antimicrobial resistance: global report on surveillance, France: WHO.pp.19,2014.

[17] P H Blomquist. Methicillin-resistant Staphylococcus aureus infections of the eye and orbit (an American Ophthalmological Society thesis). Trans Am Ophthalmol Soc; 104: 322-45,2006.

[18] A H Mohammed. Community and Healthcare Acquired Nasal Carriage of Methicillin-resistant Staphylococcus aureus in Duhok Governorate /Kurdistan Region. Ph.D. thesis. College of Medicine, Duhok University, Iraq,2013.

[19] M El-Shenawy ,M Tawfeek, L El-Hosseiny, MEl-Shenawy ,A Farag , H Baghdadi et al (2014). Cross Sectional Study of Skin Carriage and Enterotoxigenicity of Staphylococcus aureus among Food Handlers . Open J Med Microbiol; $\quad 4(1)$ : Article ID: 43014,7 ,2013. DOI:10.4236 /ojmm.2014. 41003.

[20] M Eveillard ,Y Martin , N Hidri ,Y Boussougant ， M L Joly-Guillou. Carriage of methicillin-resistant Staphylococcus aureus among hospital employees: prevalence, duration, and transmission to households. Infect Control Hosp Epidemiol.; 25(2): 114-20 ,2004.

[21] N A Pathare, S Tejani, H Asogan , G Al Mahruqi S , Al Fakhri ,R Zafarulla eal . Comparison of methicillin resistant Staphylococcus aureus in healthy community hospital visitors [CA-MRSA] and hospital staff [HA- MRSA]. Mediterr J Hematol Infect Dis;7(1):1- 6, 2015. doi.org /10. 4084 / MJHID.2015.053.

[22] J W Beam and B Buckley . Community-acquired methicillin-resistant Staphylococcus aureus: Prevalence and risk factors. $J$ Athl Train; 41(3):337-40,2006

[23] A I Hidron , E V Kourbatova , J S Halvosa , B J Terrell , L K McDougal , F C Tenover et al. Risk factors for colonization with methicillin-resistant Staphylococcus aureus (MRSA) in patients admitted to an urban hospital: emergence of community-associated MRSA nasal carriage. Clin Infect Dis; 41(2): 159$66,2005$.

[24] K M Campbell ,A F Vaughn, K L Russell, B Smith,D L Jimenez,C P Barrozo et al. Risk factors for communityassociated methicillin-resistant Staphylococcus aureus infections in an outbreak of disease among military trainees in San Diego, California, in 2002. J Clin Microbiol.; 42(9): 4050-3,2004.

[25] J Ho, M O’Donoghue , M Boost . Occupational exposure to raw meat: a newly-recognized risk factor for Staphylococcus aureus nasal colonization amongst food handlers. Int J Hyg Environ Health; 217: 24753,2014.

[26] N B Kasturwar and M Shafee. Knowledge, Practices and Prevalence of MRSA among Food Handlers. IJBMR; 2(4): $889-94,2011$.

[27] J S Ferreira ,W L Costa , E S Cerqueira , J S Carvalho , L C Oliveira , R C Almeida et al. Food handlerassociated methicillin-resistant Staphylococc aureus in public hospitals in Salvador, Brazil. Food Control; 37: 395-400, 2014. doi.org/10.1016/j. foodcont.2013.09.062.

[28] J F R Lues and I Van Tonder. The occurrence of indicator bacteria on hands and aprons of food handlers in the delicatessen sections of a retail group. Food control; 18(4): 326-32, 2007.

[29] H Shojaei , J Shooshtaripoor, M Amiri . Efficacy of simple hand-washing in reduction of microbial hand contamination of Iranian food handlers. Food Res Int; 39(5): 525-29,2006. doi:10.1016/j. foodres. 2005.10.007.

[30] R Montville, Y Chen , D W Schaffner . Glove barriers to bacterial cross- contamination between hands to food. J Food Prot; 64(6): 845-9, 2001.

[31] A R Isara , E C Isah , P V Lofor , C K Ojide. Food contamination in fast food restaurants in Benin City, Edo State, Nigeria: Implications for food hygiene and safety. Public health; 124(8):467-71,2010. doi:10.1 016 /j. puhe. 2010. 03.028.

[32] S Böcher , A Gervelmeyer, D L Monnet, K Mølbak , R L Skov. Methicillin-resistant Staphylococcus aureus: risk factors associated with community-onset infections in Denmark. J Clin Microbiol Infect; 14(10):942-8, 2018.

[33] L C Immergluck, S Jain, S M Ray, R Mayberry, S Satola , T C Parker et al. Risk of skin and soft tissue infections among children found to be Staphylococcus aureus MRSA USA300 carriers. West J Emerg Med ;18(2): 2017.

[34] L Haysom , M Cross ,R Anastasas, E Moore , S Hampton . Prevalence and Risk Factors for Methicillin-Resistant Staphylococcus aureus (MRSA) Infections in Custodial Populations: A Systematic Review. J Correct Health Care; 24(2):197-213,2018. 